\title{
PESQUISA EM EDUCAÇÃO AMBIENTAL E QUESTÕES EPISTEMOLÓGICAS: ENFRENTAMENTOS CONTEMPORÂNEOS
}

\author{
Rosa Maria Feiteiro Cavalari ${ }^{1}$ \\ Eunice Schilling Trein ${ }^{2}$
}

\section{Resumo}

Neste artigo expomos as discussões ocorridas no âmbito do Grupo de Discussão de Pesquisa (GDP) - Pesquisa em EA e Questões Epistemológicas - durante o IX Encontro de Pesquisa em Educação Ambiental (IXEPEA), realizado em Juiz de Fora (MG), no período de 13 a 16 de agosto de 2017.

Palavras-chave: Questões Epistemológicas. Pesquisa em Educação Ambiental. Educação Ambiental.

\section{RESERCH IN ENVIROMENTAL EDUCATION AND EPISTEMOLOGICAL QUESTIONS: CONTEMPORARY COPING}

\begin{abstract}
This paper exposed the discussions held within the Research Group Discussion (GDP) Research in the EA and Epistemological Questions - during the IX Meeting of Research in Environmental Education (IX EPEA), held in Juiz de Fora/MG, from 13 to 16 August 2017, which had the Theme Democracy, Public Policy and Educational Practice.
\end{abstract}

Keywords: Epistemological issues. Research in Environmental Education. Environmental Education.

\section{INVESTIGACIÓN EN EDUCACIÓN AMBIENTAL Y CUESTIONES EPISTEMOLÓGICAS: ENFRENTAMIENTOS CONTEMPORÁNEOS}

\section{Resumen}

En este artículo se exponen los debates celebrados en la discusión del Grupo de Discusión de Pesquisas (GDP) - Investigación en EA y Cuestiones Epistemológicas durante el IX Encuentro de Investigación en Educación Ambiental (IX EPEA), realizado en Juiz de Fora/MG, entre 13 y 16 de Agosto de 2017, en que se eligió el tema Democracia, Políticas Públicas y Prácticas Educativas.

Palabras clave: Cuestiones epistemológicas. Investigación en Educación Ambiental. Educación Ambiental.

\footnotetext{
${ }^{1}$ Professora Assistente Doutora da Universidade Estadual Paulista “Júlio Mesquita Filho" (UNESP) Campus do Rio Claro, São Paulo, Brasil, rosamfc@rc.unesp.br.

${ }^{2}$ Professora Titular da Universidade Federal Fluminense (UFF), Niterói, RJ, Brasil, eunicetrein@ig.com.br.
} 


\section{Introdução}

A temática proposta como eixo central do IX EPEA Democracia, Políticas Públicas e Práticas Educativas ensejou inúmeros debates sobre a temática ambiental, avanços e retrocessos que temos vivenciado na área. As conferências, mesas redondas, trabalhos apresentados e as discussões no âmbito dos Grupos de Discussão (GDPs) evidenciaram novos desafios, que estão postos para todos aqueles que se ocupam da questão ambiental.

Desde os anos setenta do século passado - e ao longo das grandes conferências em 1972, 1992 e 2012 - pudemos acompanhar a consolidação da problemática ambiental, o destaque para a relevância da educação ambiental, como espaço de conscientização dos desafios que a humanidade enfrenta para garantir sua sobrevivência, e a necessidade de acompanharmos as ações dos movimentos sociais, das políticas públicas e das práticas educativas.

Neste sentido, o GDP Pesquisa em Educação Ambiental: questões epistemológicas tem sido um espaço importante de reflexão sobre as questões que atravessam o âmbito das pesquisas, principalmente na pós-graduação em Educação Ambiental.

Durante o IX EPEA pudemos verificar a recorrência de questionamentos expressos em reuniões anteriores, que sinalizaram, não apenas para a permanência de certos desafios mas, também, para retrocessos que vivenciamos nas políticas públicas e nas práticas educativas, retrocesso este, justificado pelo poder público e pelo capital privado com a crise econômica, o desemprego, a falta de competitividade e a desinformação da população sobre os reais formadores do desenvolvimento econômico e social.

A grande interferência do setor privado no ambiente escolar é expressão disto, tanto pelo movimento Todos Pela Educação, quanto pelas parcerias público-privadas que vem ocorrendo nas práticas educativas em EA.

No acompanhamento que fizemos desse GDP, nos últimos oito anos, pudemos verificar que diversas questões continuam recorrentes, evidenciando que não estão superadas. Elencamos algumas, ainda que brevemente:

- Continuidade dos GDPs como espaço de pesquisa e sistematização histórica da produção acadêmica sobre a EA.

- Necessidade de explicitar, nas pesquisas, não apenas os procedimentos teórico-metodológicos mas, também, o contexto social em que são produzidas e os interesses socioeconômicos que as orientam.

- Necessidade de superar as fragilidades metodológicas, perguntando sobre qual solo epistemológico esses referenciais se estabelecem. ${ }^{3}$

A continuidade do debate aconteceu em 2015, quando, mais uma vez, se cobrou uma explicitação do sentido que atribuímos ao que chamamos de uma perspectiva crítica, quando nos referimos às pesquisas e às práticas em Educação Ambiental (CAVALARI; TREIN, 2016).

\footnotetext{
${ }^{3}$ Essas questões já foram tratadas, de forma mais extensa, em: TREIN (2012) e TREIN; CAVALARI (2014)
} 
Para melhor acompanharmos tais questões e outras trazidas ao IX EPEA, apresentamos os trabalhos inscritos no GDP, onde as questões epistemológicas ganham relevância.

\section{Síntese dos trabalhos inscritos no GDP Pesquisa em Educação Ambiental e Questões Epistemológicas - breves comentários}

O IX Encontro de Pesquisa em Educação Ambiental - IX EPEA, realizado sob o tema Democracia, Políticas Públicas e Práticas Educativas, no período de 13 a 16 de agosto de 2017, em Juiz de Fora, MG, no campus da Universidade Federal de Juiz de Fora, teve onze trabalhos inscritos para o GDP Pesquisa em Educação Ambiental e Questões Epistemológicas.

Em relação ao número de trabalhos inscritos, comparativamente aos dois últimos eventos, podemos observar que houve um ligeiro aumento em relação ao VIII EPEA, realizado em 2015, no Rio de Janeiro, que contou com oito trabalhos inscritos, se igualando em número de trabalhos inscritos ao VII EPEA, realizado em 2013, em Rio Claro, que também teve inscritos para esse GDP onze trabalhos. Como podemos observar, mantém-se relativamente estável, com ligeira alteração, o interesse dos pesquisadores do campo da Educação Ambiental em relação às questões epistemológicas.

Da leitura das onze pesquisas inscritas pode-se depreender que todas podem ser classificadas como pesquisas qualitativas, e todas podem ser compreendidas como tributárias da perspectiva crítica da Educação e da Educação Ambiental, a maioria explicitando claramente essa opção. Dentre essas pesquisas, cinco são pesquisas teóricas e seis relatos de pesquisas empíricas.

Em relação às pesquisas empíricas, três podem ser classificadas como pesquisa documental, uma do tipo estado da arte sobre teses e dissertações, um estudo de caso e uma não explicita o tipo de pesquisa realizada.

O corpus documental adotado pelas pesquisas do tipo documental é o seguinte: um periódico internacional de pesquisa em Educação Ambiental, Environmental Education Research, dois periódicos nacionais sobre pesquisa em Educação Ambiental: Revista do Mestrado em Educação Ambiental (REMEA) e Revista Pesquisa em Educação Ambiental (REVPEA) e o documento que fundamenta a Década da Educação para o Desenvolvimento Sustentável (DEDS), a saber, Plano Internacional de Implementação.

Acompanhando a tendência que vem sendo observada em levantamentos dessa natureza, em relação à origem dessas pesquisas, há um predomínio da região Sudeste, oito pesquisas, seguida da região Sul, com duas pesquisas e apenas uma da região Nordeste. Outra tendência observada é que todas as pesquisas foram desenvolvidas em universidades públicas, sendo oito em IES federais e três em IES estaduais.

Isto posto, passamos, a seguir, a apresentar uma síntese desses trabalhos em relação ao título, objeto de pesquisa, referencial teórico, objetivos e principais conclusões. Inicialmente, apresentamos os trabalhos por nós classificados como teóricos.

O trabalho Indivíduo Social e Formação Humana: fundamentos ontológicos de uma Educação Ambiental Crítica, elaborado por José Garajau da Silva Neto (UFRJ), apresentado pelo autor como ensaio, objetiva "discorrer sobre as categorias conceituais indivíduo e formação humana em uma leitura ontológica do ser social, entendendo que 
esta é parte constitutiva de uma perspectiva crítica da educação ambiental" (SILVA NETO, 2017, p.1).

De acordo com o autor:

A principal motivação para tal elaboração teórica está na constatação de que o discurso hegemônico na educação, e em particular na educação ambiental, elabora seus argumentos e proposições pedagógicas com base em um indivíduo autocentrado, dissociado das relações sociais, e de educação como um processo independente dos determinantes sociais, sem mediações com as relações de produção e a organização da sociedade (SILVA NETO, 2017, p.2).

Ainda, de acordo com o autor:

Isso cria uma idealização da educação e dos indivíduos, uma aposta na educação e nas 'pessoas de boa vontade' como caminho único para a superação das relações vigentes com a natureza que perde a complexidade constitutiva da existência humana. E, em termos políticos, anula a possibilidade histórica de transformação das relações sociais alienadas no capitalismo (SILVA NETO, 2017, p.2).

O autor "destaca e reitera", no artigo, "aspectos teóricos relacionados aos fundamentos ontológicos do ser social, a partir da ontologia inaugurada por Karl Marx [...] com especial atenção à obra de Gyorgy Lukács". Para esses autores e para "toda uma vasta tradição ontológica e epistêmica-política constituída a partir deles, o ser humano só pode ser compreendido e concebido na totalidade social em que os indivíduos e as múltiplas dimensões da vida humana se formam” (SILVA NETO, 2017, p.2).

Assim, "ao ser uma ontologia centrada no metabolismo sociedade-natureza (trabalho) como momento fundante do ser social, busca superar o idealismo e o objetivismo, a "naturalização" do que é socialmente produzido e a essencialização do ser humano" (SILVA NETO, 2017, p.2).

Em seguida, o autor busca discutir o "indivíduo social" no contexto do capitalismo contemporâneo, denominado pelo autor como "capitalismo pós-moderno, contribuindo com a fundamentação teórica das perspectivas críticas da educação ambiental (inscritas nessa tradição ou que com esta dialogam), principalmente naquilo que remete à ontologia do ser social" (SILVA NETO, 2017, p.3).

$\mathrm{O}$ autor encerra o artigo, afirmando que:

A ontologia do ser social, ao partir do metabolismo sociedade-natureza como fundamento do ser social, permite-nos entender que a degradação ambiental é a expressão de um sociometabolismo expropriador do trabalho e da natureza. Portanto, somente uma superação radical do modo de produção da existência social em sua forma capitalista pode gerar uma outra relação qualitativamente superior com a natureza. Afirmamos, assim, uma educação ambiental que se pense e se conceba nas relações trabalho-educação, que assuma as lutas sociais e seja encarnada pelos agentes sociais, inscritos nos movimentos antissistêmicos. Em última instância, que contribua, como princípio e como finalidade, com a construção de um outro modelo societário (SILVA NETO, 2017, p.10).

O trabalho A Formação de Educadores Ambientais na Convivência Pedagógica com outra Epistemologia em tempos de Crise de Paradigmas, de autoria de Helder Sarmento Ferreira e Mauro Guimarães, da Universidade Federal Rural do Rio de Janeiro (UFRRJ), buscou investigar as práticas e os processos formativos dos educadores ambientais na "Com Vivência" com outras epistemologias a partir de 
experiências com os Guaranis, na aldeia Guarani em formação, Ara Hovy, em Itaipuaçu, município de Maricá, Rio de Janeiro (FERREIRA; GUIMARÃES, 2017, p.1).

A pesquisa em questão, apresentada pelos autores como um ensaio, pretende, a partir das reflexões de uma dissertação de mestrado, "[...] firmar o pensamento de uma educação ambiental crítica e um processo de formação de educadores ambientais, fundamentado em uma práxis dialógica que denominamos neste estudo de 'Com Vivência’ Pedagógica" (FERREIRA; GUIMARÃES, 2017, p.1).

O ensaio é organizado por meio de dois itens, além da introdução e das considerações finais, a saber, A formação de educadores ambientais no contexto de crise paradigmática e A Com Vivência com outras epistemologias no reencontro com o natural.

Nesse último item, os autores afirmam que:

Nesse contexto de grave crise, ressalta-se a necessidade da educação ambiental contribuir com processo de transformação da realidade socioambiental. Portanto torna-se imprescindível romper com as fronteiras impostas pela força hegemônica e suas referências paradigmáticas. Uma possibilidade de grande potencial pedagógico é interagir e dialogar com distintas formas de conhecimento e outras cosmovisões em uma "Com Vivência pedagógica (FERREIRA; GUIMARÃES, 2017, p.8).

Afirmam, ainda, que:

A 'Com Vivência' com outras epistemologias, revela a capacidade de impor e opor as atuais condições de opressão com isso a pedagogicidade do diálogo com outras epistemologias no reencontro com o natural. Isso nos revelou que o caminho de um aprendizado vivenciado em uma prática educativa, zelada em um princípio libertador e dialógico, com possibilidades de profunda amorosidade como força conectiva e construtora de novas relações (FERREIRA; GUIMARÃ ES, 2017, p. 9).

Nas Considerações Finais afirma-se que:

Os aspectos e elementos da cultura Guarani puderam referenciar o processo de formação de educadores ambientais, num modo vivencial, que se fez possível entender a relevante contribuição da "Com Vivência Pedagógica" para pensarmos a construção do mundo a partir da reflexão de uma outra cosmovisão (FERREIRA; GUIMARÃES, 2017, p.10).

Encerram o artigo, afirmando que:

Para que a educação ambiental instrumentalize a transformação da realidade socioambiental, tanto no plano individual como no coletivo, o compromisso com este processo leva em consideração as transformações de percepção, que possibilitem novos saberes e fazeres. Esperamos, em uma escala ampliada, fortalecer uma contra-corrente, no que se refere à relação dos seres humanos entre si em novo modo de organização social e na relação com a natureza, vislumbrando a possibilidade de um novo mundo socioambientalmente sustentável (FERREIRA; GUIMARÃES, 2017, p. 11).

No trabalho Educação Ambiental na contemporaneidade: uma análise da conjuntura, as autoras Sama de Freitas Juliani e Laísa Maria Freire, da UFRJ, afirmam que:

[...] nesse texto, abordamos algumas características da contemporaneidade que agravam esse contexto de crise socioambiental, e apresentamos a Educação Ambiental como uma possibilidade de re (pensarmos) nossas formas de ver e agir no mundo, em busca da melhoria das condições devida das pessoas e das outras formas de vida (JULIANI; FREIRE, 2017, p.1). 
Para tanto, as autoras desenvolvem um item no qual buscam apresentar algumas das características da contemporaneidade, que "contribuem para o quadro atual de crises socioambientais globais" (JULIANI; FREIRE, 2017, p.2) e, em seguida, apresentam outro item no qual discorrem sobre a Educação Ambiental como possibilidade de enfrentamento do modelo atual de desenvolvimento da sociedade (JULIANI; FREIRE, 2017, p.5).

As autoras, fundamentadas em Castro, Spazziani e Santos, (2012) afirmam que a "Educação Ambiental (EA) tem sido considerada um importante instrumento para a promoção de mudanças nos modos dominantes do pensamento moderno e no modelo de desenvolvimento econômico".

Ainda de acordo com as autoras, fundamentadas em Sauvé (2005), na EA circulam discursos que, no entanto, são muito diferentes em relação à sua compreensão sobre Educação Ambiental, seus objetivos e formas de ação. Esses discursos, de acordo com as autoras, agora fundamentadas em Loureiro (2003), "são imbuídos de diferentes perspectivas ideológicas e, portanto, podem atuar tanto na reprodução [...] quanto na transformação desse cenário buscando a "justiça social", o equilíbrio ecossistêmico e a indissociabilidade entre humanidade-natureza" (JULIANI; FREIRE, 2017, p.5).

Em seguida, apresentam alguns trabalhos que buscam classificar a EA quanto à sua concepção, projetos educativos, ideologias etc., com o intuito de "entender as disputas ideológicas entre diferentes discursos sobre EA". Assim, apresentam-se as contribuições de Sauvé (2005) que elabora uma "cartografia das correntes em EA" na qual apresenta "quinze correntes em EA"; Guimarães (2004) que "defende existir duas principais vertentes de EA" (a conservadora e a crítica) e, finalmente, Lima e Layrargues (2014) que "identificam três macrotendências político-pedagógicas disputando a hegemonia do campo da EA no Brasil: a conservacionista, a pragmática e a crítica" (JULIANI; FREIRE, 2017, p.6).

Nas considerações finais afirmam que:

Nesse texto buscamos apontar que as transformações atuais do capital vêm acirrando um quadro de injustiças sociais e ambientais que são justificadas por meio do discurso neoliberal que trata essas reestruturações como naturais e inescapáveis. Diante disso, entendemos que a EA em sua vertente crítica desponta como uma opção a esse discurso determinista, pois tem como objetivo questionar esse modelo de desenvolvimento em busca de sua transformação para formas mais justas de produção da vida social e material (JULIANI; FREIRE, 2017, p.7).

As autoras alertam, no entanto, para as "dificuldades em desenvolver de forma prática a EA em sua vertente crítica", como tem sido apontado por alguns autores, e encerram o artigo, afirmando que: "Assim, urge identificarmos as formas e espaços de resistência, onde seja possível desenvolver ações de EA, para fortalecê-los e ampliá-los, ao invés de continuarmos a apontar as ações de EA consideradas "não tão críticas" (JULIANI; FREIRE, 2017, p.8).

Outro trabalho por nós classificado como teórico tem como título Abordagem Crítica da Educação Ambiental e Patrimonial: conexões possíveis rumo ao pensamento pós-colonial, desenvolvido por Tiago Silva Alves Muniz (UFRJN) e Barbara Cristina Pelacani (UNIRIO).

O trabalho em questão teve como objetivo "refletir sobre a necessidade de contextualização de temas transversais e atuação do educador frente às relações hegemônicas de dependência, pobreza e visão de mundo" (MUNIZ; PELACANI, 2017, p.1). 
O artigo é organizado por meio de dois itens, além da introdução e das considerações finais: no primeiro item A atuação da Educação Ambiental Crítica na perspectiva humanitária, os autores afirmam que:

[...] a finalidade primordial de atuação no campo da educação ambiental é revolucionar os indivíduos em suas subjetividades e práticas nas estruturas sócio-naturais existentes. Ou seja, estabelecer processos educativos que favoreçam a realização do movimento de constante construção do nosso ser na dinâmica da vida como um todo e de modo emancipado. Em termos concretos, isso significa atuar criticamente na superação das relações sociais vigentes, na conformação e uma ética que possa se afirmar como "ecológica" e na objetivação de um patamar societário que seja a expressão da ruptura com os padrões dominadores que caracterizam a contemporaneidade" (MUNIZ; PELACANI, 2017, p.4).

Para os autores, "o papel que assume a Educação Ambiental, portanto é o nome que historicamente se convencionou dar às práticas educativas relacionadas à questão ambiental" e, fundamentados em Layrargues (2004), concluem que: "Assim, Educação Ambiental designa uma qualidade especial que define uma classe de características que juntas, permitem o reconhecimento de sua identidade, diante de uma educação que antes não era ambiental" (MUNIZ; PELACANI, 2017, p.4).

Em seguida, os autores apresentam algumas ideias referentes à Educação Ambiental crítica, afirmando que essa educação "parte de uma visão sócio-histórica para a compreensão da atual crise ambiental a partir das relações sociedade-natureza, para chegar à intervenção sobre os conflitos ambientais" (MUNIZ; PELACANI, 2017, p.5).

Afirmam, ainda que "a Educação Ambiental crítica é uma contraposição da Conservadora em busca de outros objetivos, partindo de outros princípios conceituais e referenciais teóricos" e, tendo como referência Guimarães (2004), afirmam que:

[...] esta [a educação ambiental crítica] é uma abordagem que intenta compreender e intervir na realidade socioambiental através da complexidade mirando o conflito como ponto onde as reações de poder são fundantes na estruturação e múltiplas determinações dos sentidos e dos espaços (MUNIZ; PELACANI, 2017, p.5).

Os autores iniciam o item Educação patrimonial: situando público, tempo e espaço caracterizando a Educação Patrimonial. Esta "pode ser entendida como um processo permanente e sistemático de trabalho educacional centrado no Patrimônio Cultural como fonte primária de conhecimento e enriquecimento individual e coletivo" (MUNIZ; PELACANI, 2017, p.5).

Em seguida, tendo como referência Césaire (2006) discutem a relação colonizador/colonizado e, a partir de Hodder (2016), a "noção de armadilhas da pobreza". De acordo com os autores, "a armadilha da pobreza toma muitas formas, mas o termo é geralmente usado para descrever alguma forma (sic) o mecanismo de espiralamento através do qual as pessoas não podem sair da pobreza" (MUNIZ; PELACANI, 2017, p. 9).

Nas considerações finais, à qual os autores atribuem o subtítulo confluências $e$ perspectivas de atuação conjunta, afirmam que:

A abordagem de Educação Patrimonial e da Educação Ambiental em suas perspectivas críticas como recurso para a compreensão sócio-histórica das referências culturais e socioambientais em todas as suas manifestações do saber, colabora para seu reconhecimento, valorização e preservação. Considera-se, ainda que os processos educativos devem primar pela construção coletiva e democrática do conhecimento, por meio da participação efetiva das comunidades detentoras e produtoras das referências culturais e 
ambientais, onde convivem diversas noções de patrimônio cultural e sustentabilidade $\mathrm{cm}$ bases ambientais que podem promover a transformação social ((MUNIZ; PELACANI, 2017, p.9).

E encerram o artigo, afirmando que:

[...] A partir de um panorama de teias de emaranhamento os nódulos teias sobrepostas revelam tessituras sobre os aspectos que podem ser trabalhados sob a ótica de debates em patrimônio cultural e educação ambiental, com características da trans e interdisciplinares sócio-histórica-ambiental definidas a partir de relações espaço temporais. Na busca de uma ciência póscolonial que se proponha a romper com a colonização do pensamento, tratando de se apropriar das conexões possíveis entre a abordagem crítica da educação ambiental e patrimonial rumo à transformação (MUNIZ; PELACANI, 2017, p.10).

O último trabalho por nós caracterizado como teórico, inscrito nesse GDP, foi desenvolvido por Heluane Aparecida Lemos de Souza e Rosa Maria Feiteiro Cavalari e tem como título Relação Ética Entre Sociedade e Natureza: contribuições da obra $O$ Princípio Responsabilidade, de Hans Jonas, para a educação Ambiental. De acordo com as autoras:

[...] o presente estudo, um diálogo com a obra 'O princípio responsabilidade: ensaio de uma ética para a civilização tecnológica', do filósofo alemão Hans Jonas (1903-1993), busca apresentar contribuições para a Educação Ambiental quanto à questão da relação ética entre seres humanos e demais elementos da natureza, evidenciando as reflexões que a obra de Jonas suscita a respeito do agir humano em relação à natureza não humana, em sua dimensão axiológica (SOUZA; CAVALARI, 2017, p.1).

Fundamentadas em Jonas, na obra já citada, as autoras afirmam que:

A ética antiga já não mais responde às mudanças provocadas pela técnica moderna, dados os novos objetivos, consequências das ações, assim como o caráter extraordinário do novo poder do homem [...]. Isso impõe à ética uma nova dimensão de responsabilidade. [...] Isso possibilita perceber a modificação da natureza do agir humano, e reconhecer um objeto de nova ordem, a biosfera, como responsabilidade desse agir, algo a ser considerado em uma 'nova teoria ética' (SOUZA; CAVALARI, 2017, p.2).

Ainda, de acordo com o trabalho:

Jonas indaga se, com o novo agir humano, seu poder de intervenção e modificação não apenas na esfera humana, mas também na 'natureza extrahumana' não deveria a natureza ser incluída em nossa esfera moral, não em uma relação antropocêntrica, utilitária, mas por um direito próprio (SOUZA; CAVALARI, 2017, p.3).

Essa inclusão, no entanto, de acordo com o trabalho:

Implicaria em modificações nos fundamentos da ética, implicações da consideração das coisas extra-humanas como 'fins em si' e a procura do bem para elas, e não apenas o bem humano. Isso ao contrário do que nos foi legado pela ciência, que se recusa a 'pensar a natureza como algo que devamos respeitar' (SOUZA; CAVALARI, 2017, p.3).

Ainda de acordo com o trabalho, "destaca-se que, para Jonas (2006), a prudência deverá estar no cerne do nosso agir moral, assim como, na nova ética a ser fundada, o 'princípio responsabilidade' tem de ser independente das ideias de direito e de reciprocidade" (JONAS, 2006 apud SOUZA; CAVALARI, 2017, p.4). 
Após apresentar aspectos importantes do pensamento do autor, discutidos na obra, particularmente a noção de responsabilidade, as autoras defendem que:

[...] as discussões que venham a ser empreendidas sobre a relação ética entre humano e natureza não humana, discussões urgentes e necessárias, devem ocorrer dentro da campo da ética, buscando refletir sobre seus fundamentos. Hans Jonas, sem postular uma 'ética ambiental', inclui na esfera moral do homem e, portanto, dentro da teoria ética, a natureza extra-humana, dado o poder de interferência e destruição possibilitado ao agir humano pela técnica moderna (SOUZA; CAVALARI, 2017, p12).

As autoras finalizam o artigo, afirmando que:

A possibilidade de ampliação da esfera moral, incluindo a natureza nãohumana, implica para a Educação e, particularmente para a Educação Ambiental, a necessidade de discutir os valores que a norteiam, dado que passa a objetivar não apenas relações mais equilibradas e justas entre os homens, mas entre o homem e a natureza não humana (SOUZA; CAVALARI, 2017, p.12).

Tendo apresentado as sínteses dos trabalhos teóricos, apresentamos, na continuidade, as sínteses relativas às pesquisas empíricas.

O trabalho Práxis Pedagógica na Formação Profissional do Assistente Social: caminhos para promoção de Educação Ambiental, de autoria de Tatiana Ferreira dos Santos e Maria Inêz Oliveira Araujo, apresenta resultados de uma dissertação de mestrado e tem como objetivo:

Evidenciar a práxis pedagógica desenvolvida na disciplina "Realidade Regional" e na disciplina "Movimentos Sociais e Serviço Social" do curso de Serviço Social da Universidade Federal de Sergipe que levam ao trato da questão ambiental na formação inicial profissional do assistente social (SANTOS; ARAUJO, 2017, p.2).

De acordo com as autoras, a pesquisa "tem caráter exploratório e abordagem qualitativa por meio do estudo de caso e utilizou para coleta de dados fontes documentais, tais como, "Diretrizes Curriculares Nacionais para o curso de Serviço Social; Diretrizes Curriculares Gerais para o curso de Serviço Social; Diretrizes Curriculares Nacionais para a Educação Ambiental; Política Nacional de Educação Ambiental; Código de Ética do Assistente Social de 1993", além do "Projeto Político Pedagógico do Curso de Serviço Social, Planos de Disciplinas e Ementas da UFS e Estruturas Curriculares de ambas as instituições (SANTOS; ARAUJO, 2017, p.3)

As autoras informam que "concomitante à análise documental, oito alunos concludentes do curso de Serviço Social participaram da pesquisa através de questionários abertos" e que a partir da análise documental e do questionário respondido pelos alunos "evidenciou-se as disciplinas Movimentos Sociais e Serviço Social e Realidade Regional". Assim sendo, "apenas uma docente responsável pelas disciplinas participou de uma entrevista semiestruturada" (SANTOS; ARAÚJO, 2017, p.3)

Informam, ainda, que "para a análise dos dados utilizou-se o método de Análise Textual Discursiva (ATD)", e que a pesquisa "fundamenta-se na Educação Ambiental Crítica, cujas bases norteiam-se a partir da totalidade concreta considerando o movimento dialético e histórico das relações sociais, que questionam o modo capitalista de produção formando sujeitos críticos e conscientes da realidade [...] (SANTOS, ARAÚJO, 2017, p. 3).

As autoras concluem o artigo, afirmando que: 
Apesar desta dimensão [ambiental] se situar em apenas duas disciplinas e, de fato, pouco presente em documentos oficiais curriculares específicos para o curso de Serviço Social, produções e publicações, os relatos aqui em questão demonstram possibilidades para se repensar a formação profissional, a fim de incluir cada vez mais a realidade concreta de forma dialógica com o projeto da profissão. Este repensar não é reflexo da ausência ou insuficiência do debate ambiental na disciplina aqui explicitada, mas reflexo das experiências da professora e alunos que demandam por formação que esteja cada vez mais próxima à realidade, sobretudo acompanhando as modificações da dinâmica da sociedade (SANTOS; ARAUJO, 2017, p.10).

O trabalho Quilombo Maria Conga-RJ: dialogicidade em Educação Ambiental, de autoria de Gabriel dos Santos Martins e Mauro Guimarães, da UFRRJ, tem como objetivo:

[...] apresentar os resultados preliminares de uma pesquisa que tem como princípio a importância do diálogo com outros saberes, através do Quilombo Maria Conga-RJ, para a consolidação de processos práticos-formativos em Educação Ambiental (EA). Pretende-se, assim, a constituição e valorização de outros princípios, outras referências, capazes de tensionar o paradigma dominante/homogeneizante de forma reflexiva e crítica (MARTINS; GUIMARÃES, 2017, p.2).

Para o desenvolvimento da pesquisa os autores informam que "além da revisão bibliográfica, foi realizado um trabalho de campo no Quilombo, composto por entrevista aberta com alguns sujeitos da comunidade, para a aproximação/apresentação" (MARTINS; GUIMARÃES, 2017, p.2).

Informam, ainda, que essa aproximação foi "não direcionada à sistematização das falas, nos parâmetros metodológicos que envolvem procedimentos como a gravação ou o registro imediato". Tendo como referência Sánchez et al (2010) afirmam que "a base dialógica foi composta, nesse momento, apenas pela escuta sensível" (MARTINS; GUIMARÃ̃ES, 2017, p.2).

De acordo com os autores:

Como aporte teórico-metodológico interpretativo, relaciona-se a opção decolonial do saber, como forma de problematização da imposição de uma racionalidade através das relações de poder fundantes da estrutura hegemônica. Crítica que se pauta na busca do saber ambiental e que se estabelece pela dialogicidade com outros saberes (LEFF, 2008 apud MARTINS; GUIMAR ̃̃ES, 2017, p.4).

Assim sendo, após a discussão relativa à "decolonialidade do saber e emergência de outras racionalidades" (MARTINS; GUIMARÃES, 2017,p.4), bem como da descrição da experiência vivida no Quilombo Maria Conga, os autores, nas considerações finais, afirmam que:

O Quilombo Maria Conga é um dos múltiplos e variados exemplos de comunidades tradicionais com as quais podemos estar buscando essas novas referências para a constituição de novos paradigmas. Constituição por meio de processos prático-formativos que configure, enquanto centralidade, a integração ao natural, pautados no respeito, na cooperação (MARTINS; GUIMARÃES, 2017, p.9).

E encerram o artigo, afirmando que:

Nesse primeiro campo já aponta um grande indicador para pensarmos processos formativos de EA pela minha própria experiência vivenciada. Se formos voltados para uma escrita sensível e aberto a amorosidade da dialogicidade ao diferente, não se passa incólume por uma Vicência como essa. Outras experiências virão (MARTINS; GUIMARÃES, 2017, p.9). 
Como já apontado, dentre os trabalhos que relatam pesquisas empíricas, três foram desenvolvidos por meio de pesquisa documental. Desses, dois tiveram como corpus documental periódicos do campo da Educação Ambiental, um referente a periódicos nacionais e outro a um periódico internacional.

Um desses trabalhos tem como título Referências Epistemológicas Presentes nas Revistas PEA e REMEA no período de 2004 a 2016 sob a Perspectiva Crítico Dialético (sic), de autoria de Maria Júlia Meneghel Benatto e Jorge Sobral da Silva Maia, da Universidade Estadual do Norte do Paraná (UENP).

De acordo com os autores, trata-se de uma pesquisa em desenvolvimento, que tem como objetivo "elaborar uma análise crítica dos fundamentos teóricos da Educação Ambiental em periódicos nacionais REMEA e PEA do campo teórico da educação Ambiental nos últimos dez anos sob uma perspectiva crítico-dialética" (BENATTO; MAIA, 2017, p.2).

$\mathrm{Na}$ metodologia os autores informam que:

Adotamos a abordagem qualitativa apoiada no método dialético, pois este permite enfatizarmos a dimensão histórica dos processos sociais e suas intricadas relações na captação e interpretação dos fenômenos a serem estudados. No delineamento da pesquisa o método dialético em seu componente histórico constitui-se também como o sistema conceitual para fundamentar o estudo (BENATTO; MAIA, 2017, p.2).

Os autores descrevem, de forma detalhada, os critérios utilizados para a seleção do corpus documental da pesquisa:

Adotou-se como metodologia a revisão sistemática e o critério de inclusão para as revistas é serem especializadas em pesquisas em educação ambiental. Para os artigos os critérios são os fundamentos epistemológicos: Fenomenologia, Hermenêutica e Crítica-Dialética. Foram identificados 732 artigos na REMEA e selecionados 80. Na PEA foram identificados 204 e selecionados 23. Na perspectiva crítico-dialética adotando os critérios Crítica, Dialética, Materialismo e Marxismo foram selecionados 10 artigos na REMEA e 4 na PEA (BENATTO; MAIA, 2017, p.1).

Após a análise e discussão desses periódicos, na conclusão os autores afirmam que:

Nossa percepção nos indica que a utilização da revisão sistemática mostrouse eficiente para a coleta de dados que nos propomos e possibilitou, por meio dos critérios adotados, reconhecer indicativos dos caminhos percorridos nestes dez anos na produção em educação ambiental. Indicou, também, vasta produção teórico-prática na área, apontando forte qualificação para o campo. Todavia, verificou-se limitado diálogo com a vertente histórico-crítica o que indica, em linhas gerais, que este referencial epistemológico é pouco utilizado no país, seja por desinteresse dos pesquisadores ou esta produção pode estar publicada em periódicos não específicos da área de educação ambiental que são poucos no país (BENATTO; MAIA, 2017, p.9).

Encerram o artigo com a seguinte afirmação:

Ainda podemos considerar que diante das mazelas impostas pela acumulação privada de capital e da expropriação e exploração do capital e do estado sobre o trabalho que podemos entender, está na base da degradação humana e ambiental, o referencial epistemológico crítico-dialético é ainda o mais qualificado para realizar o enfrentamento necessário para a produção de conhecimento científico, artístico e filosófico com vistas a superar este modo pernicioso de produzir a vida em sociedade (BENATTO; MAIA, 2017, p.9). 
O trabalho que analisa o periódico internacional no campo da Educação Ambiental tem como título Uma leitura da Educação Ambiental Crítica no Periódico Environmental Education Research por meio da revisão sistemática, de autoria de Pâmela Angélica da Costa e Jorge Sobral da Silva Maia, também da Universidade Estadual do Norte do Paraná (UENP).

O trabalho em questão tem como objetivo:

Elaborar uma análise crítica dos fundamentos epistemológicos críticodialéticos da educação ambiental em um periódico internacional do campo teórico da educação ambiental nos últimos dez anos, evidenciando como aborda a educação ambiental crítica no processo de emancipação humana no âmbito da sociedade contemporânea (COSTA; MAIA, 2017, p.1).

Na metodologia os autores informam que:

Optamos aqui pelo método dialético por considera-lo conveniente para a realidade social, ao ponto de tomarmos uma postura metodológica específica para essa realidade no sentido em que não se aplica à realidade natural, porque esta é destituída do fenômeno histórico subjetivo. Nem por isso deixará de conviver com estruturas da lógica, pelo que faz sentido falarmos de lógica dialética (COSTA; MAIA, 2017, p.3).

Ainda, de acordo com os autores:

Foi realizada uma busca na revista Environmental Education Research utilizando os termos Crítica, Dialética, Materialismo e Marxismo em inglês, no período entre 2006 a 2015, notadamente verificou-se um número relativamente pequeno de artigos com estas temáticas, no total foram considerados 519 e encontrados 26, dentre os quais 21 tratam de forma explícita sobre os diversos temas que permeiam o materialismo históricodialético na pesquisa em educação ambiental (COSTA; MAIA, 2017, p.4).

Seguindo a mesma estrutura redacional do artigo que analisou os periódicos nacionais, os autores, após discutir os dados, na conclusão afirmam que, embora o "estudo seja preliminar aponta para duas questões que consideram importantes" (COSTA; MAIA, 2017, p.8)

A primeira é a utilização da revisão sistemática para estudos no campo teórico da educação ambiental. [...]. Focamos, por conta de nossa opção teórica e prática à transformação da condição de exploração a que estão submetidos os seres humanos, na perspectiva crítico-dialética e ficou evidente a carência de trabalhos de pesquisa que adotem este referencial teórico-metodológico. A segunda questão está na necessidade de entendermos que esta ocorrência pode ter diversas causas que precisam ser exploradas pelos pesquisadores que fundamentam seus estudos na perspectiva crítica [...] (COSTA; MAIA, 2017, p.8).

Os autores encerram o artigo, afirmando que:

Por isso entendemos que a educação ambiental crítica, transformadora e emancipatória e aqueles que pesquisam, ensinam e militam em seu fundamento epistemológico, têm relevante papel na mudança do cenário que se apresenta de crise global de caráter social, econômico, político e ambiental, na luta contra o avanço do capital e do Estado sobre o trabalho em favor de uma classe social hegemônica cujo fim último está na dominação e expropriação da riqueza material e ambiental (COSTA; MAIA, 2017, p.9).

O trabalho Análise da Década da Educação para o Desenvolvimento Sustentável (DEDS) da UNESCO a partir da Leitura da Pedagogia da Autonomia de Paulo Freire, de autoria de Rafaella Uchôa; Leonardo de Castro e Celso Sánchez, da UNIRIO, "discute as concepções de sustentabilidade e as propostas pedagógicas da Década da 
Educação para o desenvolvimento Sustentável (DEDS) da UNESCO (Organização das Nações Unidas para a Educação, a Ciência e a Cultura) sob a ótica da perspectiva de educação de Paulo Freire (UCHÔA; CASTRO; SÁNCHEZ, 2017, p. 1)

Os autores afirmam que:

Através de uma análise do documento que fundamenta a DEDS, especificamente o Plano Internacional de Implementação, publicado em 2005, procurou-se identificar categorias em Paulo Freire, mais precisamente, de sua obra Pedagogia da Autonomia, que sustentam as contribuições de suas ideias para uma educação ambiental crítica, transformadora e emancipatória (UCHÔA; CASTRO; SÁNCHEZ, 2017, p.1).

Explanam, ainda, que:

A partir da metodologia de Análise Documental, a pesquisa buscou compreender como a DEDS reforça a ideia de educação voltada para uma concepção de desenvolvimento que traz em seu bojo o reforço da centralidade do crescimento econômico; o que vem sendo proposto desde o Relatório Brundtland e ao longo dos documentos subsequentes (UCHÔA; CASTRO; SÁNCHEZ, 2017, p.1).

Ao longo do artigo, os autores buscam analisar o referido documento comparando-o com alguns conceitos e ideias de Paulo Freire, como por exemplo, criticidade, educação bancária, pedagogia do oprimido.

Ao final do artigo, nas considerações finais, os autores afirmam que:

A análise de trechos do documento da DEDS através de conceitos de Paulo Freire representa uma alternativa para perspectivas da Educação Ambiental Crítica e neste trabalho em específico, nos coloca em um lugar que nos possibilita visualizar os caminhos possíveis de se romper com uma educação colonizadora e consensual (UCHÔA; CASTRO; SÁNCHEZ, 2017, p.9).

Os autores encerram o artigo com a seguinte afirmação:

[...] sugere-se que o documento não dá conta de discutir (não responde) as problemáticas e discussões que constituem a crise ambiental, no apagamento da dimensão histórica dos problemas ambientais, na proposição de uma educação ambiental que se afasta de seu próprio compromisso crítico na construção e no exercício da cidadania. Isto aparece na forma de um discurso que pode ser interpretado como instrumentalista, representado no cumprimento de metas e agendas (UCHÔA; CASTRO; SÁNCHEZ, 2017, p.9).

Finalmente, um último trabalho empírico foi inscrito no GDP Pesquisas em Educação Ambiental e questões epistemológicas. Trata-se do trabalho A Ecopedagogia na produção acadêmica nacional em Educação Ambiental: uma análise de dissertações e teses (1981-2012), de autoria de Henrique Trawitzki e Juliana Rink, da Universidade Federal de São Carlos (UFSCar).

O trabalho em questão, do tipo estado da arte, teve como objetivo:

Analisar a abordagem da Ecopedagogia na pesquisa acadêmica brasileira em EA, apontando seus principais referenciais teóricos e suas diferentes leituras no que diz respeito à relação homem-natureza que ora apresentam-se como Dualista/Reducionistas, ora complexas/Conjuntivas, ora como Híbridas (TRAWITZKI; RINK, 2017, p. 3).

Os autores informam que a pesquisa que "está circunscrita ao âmbito do banco de teses e dissertações do Projeto EArte", projeto interinstitucional que inicialmente contava com a participação da UNICAMP, UNESP, campus de Rio Claro e USP campus de Ribeirão Preto e, atualmente conta com a participação de mais cinco IES, a 
saber, UFF,UFPR,UFSCar, UFTM e IFSP - Itapetininga, foi desenvolvida a partir da seguinte "questão norteadora": "Quais referenciais teóricos e abordagens de Ecopedagogia estão presentes nas teses e dissertações brasileiras em Educação Ambiental produzidas no período compreendido entre 1981-2012)" (TRAWITZKI; RINK, 2017, p. 3).

Os procedimentos metodológicos estão claramente explicitados no trabalho, ou seja, o levantamento dos documentos foi realizado no final do ano de 2016, "através da plataforma de busca do projeto, a partir da palavra-chave "ecopedagogia" na opção "qualquer campo"” (TRAWITZKI; RINK, 2017, p.6). Assim:

Foram resgatadas 27 teses e dissertações. Acreditando que a análise dos resumos era insuficiente para efetiva inclusão/exclusão das obras no corpus documental, optou-se pela obtenção dos trabalhos completos. Infelizmente, não tivemos acesso a 6 obras. Após a leitura e análise das 21 demais, 5 foram excluídas por não apresentarem a Ecopedagogia como um conceito chave para a proposta e/ou fundamentação conceitual da pesquisa, limitando-se a citar a palavra no resumo, por exemplo. Assim, um total de 16 estudos foram efetivamente classificados e analisados (TRAWITZKI; RINK, 2017, p. 6).

Os autores informam que a análise desse material foi realizada a partir de dois grupos de descritores: Descritores Gerais e Descritores Específicos. Estes últimos se referem às "diferentes leituras acerca da relação homem-natureza", em outros termos, à forma de abordagem da Ecopedagogia, ou seja: "Dualista/ Reducionista; Complexa/Conjuntiva ou Híbrida" (TRAWITZKI; RINK, 2017, p.6).

Após as análises, os autores apresentam os seguintes resultados:

Dentre as 16 teses e dissertações, um total de $10(62,5 \%)$ foram entendidas como Híbridas; 4 (25\%) apresentaram uma visão predominantemente alinhada com a perspectiva Complexa/Conjuntiva e, finalmente, 2 trabalhos (12.5\% _ aproximaram-se de uma leitura Dualista/Reducionista. O grupo das obras Híbridas foi constituído por 10 trabalhos - todos dissertações de mestrado (TRAWITZKI; RINK, 2017, p.8).

Em relação aos referenciais teóricos adotados afirmam que:

Moacir Gadotti foi o mais recorrente, ocorrendo em todas as 16 teses e dissertações (100\%), seguido por Freire em 14 (87,5\%), Gutiérrez e Prado em 9 (56,25\%), Fritjof Capra em 8 (50\%) e Edgar Morin em 6 (37,5\%) Também identificamos a presença de autores como Ruscheinsky, Avanzi e Boff em 4 trabalhos (25\%) (TRAWITZKI; RINK, 2017, p.10).

Nas considerações finais, os autores afirmam que o fato de o trabalho ter apontado para o predomínio de leituras híbridas, apesar da amostragem pequena, "isso é considerado positivo" (TRAWITZKI; RINK, 2017, p. 11).

Pois sugere que o debate acerca da crise socioambiental e a produção acadêmica nacional em Ecopedagogia estão num percurso de transição entre teorias e ideias que privilegiam aspectos racionais e fragmentários (de décadas atrás, mais ainda presentes) para teorias e ideias que abordam a crise ambiental de maneira integradora e cada vez mais dialógica - não no sentido de substituir o velho pelo novo, mas sim de criar novas leituras, ampliar fronteiras, transformar os processos educativos e a produção de conhecimento (TRAWITZKI; RINK, 2017, p.11).

Os autores encerram o artigo, afirmando que:

[...] não é cabível considerar uma leitura mais desejável ou mais aceita que outra - seja ela Híbrida, Complexa ou Reducionista. É através do diálogo entre o diferente que podemos (e devemos) alimentar uma permanente discussão acerca das questões socioambientais e dos processos educativos, de forma que o conhecimento continue a se transformar e a transformar, 


\begin{abstract}
consequentemente nossa realidade física, social e relacional. A construção de novas leituras de mundo se dá, simultaneamente, de maneira solidária e conflituosa, ordenada e desordenada. O conflito é tão desejável quanto a cooperação, assim como a ordem só existe em sua relação paradoxal com a desordem. É nesse cenário que é possível entender a Ecopedagogia como um elo integrador capaz de fazer dialogar e cooperar diversas leituras de mundo e áreas do saber (TRAWITZKI; RINK, 2017, p.11).
\end{abstract}

Tendo apresentado uma síntese das principais ideias dos trabalhos inscritos nesse GDP, passamos, a seguir, a apresentar um relato das discussões ocorridas nos dois momentos nos quais os participantes do GDP se reuniram durante o evento.

No primeiro dia, dos onze trabalhos inscritos no GDP, apenas os autores de três trabalhos estiveram presentes.

Consultando os outros dezesseis participantes presentes, pudemos constatar que alguns desconheciam a finalidade e a natureza dos GDPs, outros, mesmo conhecendo a dinâmica do EPEA e a finalidade dos GDPs, preferiram - embora tivessem inscritos seus trabalhos em outros GDPs - participar do GDP Pesquisa em Educação Ambiental e Questões Epistemológicas, no intuito de discutir questões relativas a esse GDP.

Em algumas manifestações se evidenciou uma carência de interlocução sobre determinados referenciais teóricos nas instituições de origem dos professores/pesquisadores participantes do GDP e, por isso, o EPEA e, por extensão, os GDPs são considerados espaços nos quais se pode debater acerca de diferentes correntes de pensamento, o que, segundo os presentes, fortalece os professores em suas atividades cotidianas.

Além disso, duas questões que têm sido recorrentes nesse GDP, em eventos anteriores, foram enunciadas: a explicitação do que é Educação Ambiental Crítica e a fragilidade teórico-metodológica observada em algumas pesquisas em educação ambiental e que se evidenciaram, também, em alguns trabalhos apresentados no IX EPEA.

No segundo dia, que contou com a participação de catorze pesquisadores, foi apontada a necessidade de, nas nossas pesquisas, ao fazermos a crítica à Ciência ou à modernidade, por exemplo, não perdermos de vista a materialidade histórica na qual estas se constituíram. Isto porque, ao não levarmos isso em conta, estamos atribuindo à Ciência ou à Modernidade o papel de instituidora da realidade, ao invés de compreendêlas como resultado de um contexto material e histórico.

Outra questão apontada diz respeito à fragilidade teórica quando da interlocução com atores contemporâneos, omitimos ou desconhecemos a interlocução desses autores com os que os precederam.

Também foi apontada a preocupação ao se propor a valorização de outros saberes, não acabar por excluir ou desqualificar o conhecimento científico como um todo, quando o que deveria ser criticado é o conhecimento hegemônico. Ademais, o que deveria ser valorizado é o direito ao acesso a todas as formas de conhecimento, sem hierarquizá-los como superiores ou inferiores.

Outro risco apontado foi o de que a descontextualização da produção do conhecimento pode resultar em um processo de fetiche da teoria.

Finalmente, um outro aspecto foi apontado, a saber, muitos pesquisadores, sobretudo aqueles cuja formação inicial não se fez no campo das chamadas humanidades, se ressentem de uma maior interlocução com o campo da Educação e, principalmente, com os conhecimentos relativos aos fundamentos teóricometodológicos dessa área de conhecimento. 


\section{Considerações Finais}

Ao longo de todo o IX EPEA, tanto nas apresentações de trabalhos, quanto nos grupos de discussões e nas palestras gerais, pudemos constatar preocupações recorrentes, que dizem respeito aos aspectos teórico-metodológicos das pesquisas, à necessidade de contextualizá-las em seus aspectos sócio-históricos, bem como atentar para os diferentes sujeitos sociais que são alvos das práticas educativas em EA.

Os debates sobre as diferentes culturas, que permeiam a sociedade brasileira em diálogo com as culturas latino-americanas, expressaram a riqueza de possibilidades, tanto teóricas quanto práticas, no que diz respeito à temática ambiental e, em especial, à EA.

Por outro lado, por diversas vezes, os participantes do encontro manifestaram sua preocupação com os retrocessos que a temática vem enfrentando, nacional e internacionalmente, por entenderem que isto compromete a questão ambiental nos âmbitos escolhidos como tema do IX EPEA: democracia, políticas públicas e prática educativa.

O objetivo expresso pelos organizadores do evento e pelos participantes, de discutir sobre essas questões, buscando afirmar os direitos de todos os seres humanos a uma participação mais igualitária no usufruto dos bens culturais, políticos, sociais, econômicos e ambientais, apontou para os enfrentamentos que se apresentam, hoje, como necessários.

Pensamos que tais enfrentamentos não nos permitem posturas ingênuas quanto ao papel da EA na transformação social. Termos clareza sobre quais são os desafios postos, hoje, pelo capital, nos ajudará a escolher com mais precisão nossos objetos de pesquisa e os referenciais teóricos e metodológicos necessários para desvendar as múltiplas faces dos complexos problemas com os quais a sociedade humana está tratando.

Gramsci nos ensinou a viver com o otimismo da ação e o pessimismo da razão. Mais do que nunca, isto se torna necessário quando atentamos para os argumentos de David Harvey (2016) em seu livro "17 Contradições e o fim do capitalismo", no qual elenca quatro argumentos que devemos considerar para não sermos ingênuos $\mathrm{e}$ julgarmos que a contradição capital-natureza, inexoravelmente, levará ao fim do atual padrão societário.

$\mathrm{O}$ primeiro argumento diz respeito ao êxito do capital em mobilizar o conhecimento científico e tecnológico para resolver problemas ambientais graves, tais como a má qualidade do ar, a falta de água, a perda da fertilidade do solo, a diminuição da biodiversidade, entre outros.

O segundo argumento elencado por Harvey diz respeito ao enfrentamento das teses muitas vezes utilizadas nos discursos ambientalistas, quando dizem que a natureza se vinga ao ser muito explorada. $\mathrm{O}$ autor contra argumenta, dizendo que o capital vem internalizando, na circulação e na acumulação, os gastos no enfrentamento desses problemas, produzindo novos produtos para o mercado que mitigam os impactos provocados pela ação humana. Aí se incluem a engenharia genética, a produção de novos compostos bioquímicos, o desenvolvimento de tecnologias captadoras de energias renováveis etc.

O terceiro argumento sinaliza a grande quantidade de novas mercadorias sob o denominado selo verde, o que induz a um aumento permanente do consumo de produtos ditos ecologicamente corretos, ampliando, assim, nichos de mercado com maior valor agregado. 
Por fim, Harvey aponta para um quarto argumento, que, muitas vezes, é dificilmente detectado, mas é muito significativo, ou seja, quais catástrofes ambientais podem ser fonte de lucro para o capital. Se olharmos para a mais recente e gigantesca catástrofe ambiental no Brasil - o rompimento das barragens de rejeitos em Mariana/ MG - veremos como as populações da região foram duramente atingidas; o ecossistema fortemente impactado e até hoje medidas reparadoras não chegaram aos habitantes dos municípios, nem as empresas causadoras foram devidamente responsabilizadas e penalizadas. No rastro da destruição foram necessários inúmeros serviços de empresas e especialistas, gerando demandas de ciência e tecnologia, que movimentaram grandes quantidades de capital, geraram novas exigências de infraestrutura, mobilizaram recursos públicos, econômicos e sociais.

Todos os aspectos analisados nos quatro argumentos nos parecem suficientes para exemplificar a complexidade dos desafios impostos aos que pretendem trabalhar as questões ambientais de forma crítica.

No GDP, mais uma vez, ganhou destaque a necessidade de aprofundarmos, teórica e metodologicamente, os sentidos que atribuímos a uma perspectiva crítica em Educação Ambiental. Como ocorreu em eventos anteriores, a maior parte dos autores dos trabalhos inscritos não compareceu, no entanto, o GDP contou com uma frequência expressiva de participantes, que expressaram interesse no aprofundamento das questões epistemológicas, pois constatam carências de diálogo sobre esses temas em suas instituições de origem.

O acompanhamento que fizemos ao longo dos anos no Grupo de Discussão de Pesquisa em EA e Questões Epistemológicas nos leva a reafirmar a importância da existência do GDP, mas também de encontrarmos, talvez, outra forma de aproximação entre as sessões de apresentação de trabalhos e os Grupos de Discussão.

\section{Referências}

BENATTO, M. J. M.; MAIA, J. S. da S. Referências Epistemológicas Presentes nas Revistas PEA e REMEA, no período de 2004 a 2016, sob a perspectiva Crítico-Dialética. In ENCONTRO PESQUISA EM EDUCAÇÃO AMBIENTAL, 9, 2017, Juiz de Fora. Anais... Juiz de Fora: UFJF, 2017. p. 1-9. Disponível em: http://epea.tmp.br/epea2017_anais/pdfs/plenary/0229.pdf. Acesso em: 5 ago. 2018.

CAVAlARI, R. M. F.; TREIN, E. Pesquisa em Educação Ambiental e Questões Epistemológicas: a necessidade da continuidade do debate. Pesquisa em Educação Ambiental, Rio Claro, v. 11, n. 2, p.83-96, jul./dez., 2016.

COSTA, P. A. da; MAIA, J. S. da S. Uma leitura da Educação Ambiental Crítica no Periódico Environmental Education Research por meio da revisão Sistemática. In ENCONTRO PESQUISA EM EDUCAÇÃO AMBIENTAL, 9, 2017, Juiz de Fora. Anais... Juiz de Fora: UFJF, 2017. p. 1-10. Disponível em: http://epea.tmp.br/epea2017_anais/pdfs/plenary/0170.pdf. Acesso em: 5 ago. 2018.

FERREIRA, H. S.; GUIMARÃES, M. A Formação de Educadores Ambientais na 'Convivência Pedagógica' com outra epistemologia em tempos de crise de paradigmas. In ENCONTRO PESQUISA EM EDUCAÇÃO AMBIENTAL, 9, 2017, Juiz de Fora. Anais... Juiz de Fora: UFJF, 2017. p. 1-11. Disponível em: epea.tmp.br/epea2017_anais/pdfs/plenary/0067.pdf. Acesso em: 5 ago. 2018.

HARVEY, D. 17 contradições e o fim do capitalismo. São Paulo: Boitempo, 2016. 
JULIANI, S. de F.; FREIRE, L. M. Educação Ambiental na contemporaneidade: uma análise de conjuntura. In ENCONTRO PESQUISA EM EDUCAÇÃO AMBIENTAL, 9, 2017, Juiz de Fora. Anais... Juiz de Fora: UFJF, 2017. p. 1-10. Disponível em: http://epea.tmp.br/epea2017_anais/pdfs/plenary/0003.pdf. A Acesso em: 5 ago. 2018.

MARTINS, G. dos S.; GUIMARÃES, M. Quilombo Maria Conga- RJ: dialogicidade em Educação Ambiental. In ENCONTRO PESQUISA EM EDUCAÇÃO AMBIENTAL, 9, 2017, Juiz de Fora. Anais... Juiz de Fora: UFJF, 2017. p. 1-11. Disponível em: http://epea.tmp.br/epea2017_anais/pdfs/plenary/0212.pdf. Acesso em: 5 ago. 2018.

MUNIZ, T. S. A.; PELACANI, B. C. Abordagem Crítica da Educação Ambiental e Patrimonial: conexões possíveis rumo ao pensamento pós-colonial. In ENCONTRO PESQUISA EM EDUCAÇÃO AMBIENTAL, 9, 2017, Juiz de Fora. Anais... Juiz de Fora: UFJF, 2017. p. 1-10. Disponível em: http://epea.tmp.br/epea2017_anais/pdfs/plenary/0225.pdf. Acesso em: 5 ago. 2018.

SANTOS, T. F. dos; ARAÚJO, M. I. de O. Práxis Pedagógica na Formação do Assistente Social: caminhos para a promoção da Educação Ambiental. In ENCONTRO PESQUISA EM EDUCAÇÃO AMBIENTAL, 9, 2017, Juiz de Fora. Anais... Juiz de Fora: UFJF, 2017. p. 1-11. Disponível em: http://epea.tmp.br/epea2017_anais/pdfs/plenary/0046.pdf. Acesso em: 5 ago. 2018.

SILVA NETO, J. G. da. Indivíduo Social e Formação Humana: fundamentos ontológicos de uma Educação Ambiental Crítica. In ENCONTRO PESQUISA EM EDUCAÇÃO AMBIENTAL, 9, 2017, Juiz de Fora. Anais... Juiz de Fora: UFJF, 2017. p. 1-10. Disponível em: epea.tmp.br/epea2017_anais/pdfs/plenary/0076.pdf. Acesso em: 5 ago. 2018.

SOUZA, H. A. L. de; CAVALARI, R. M.F. Relação Ética entre Sociedade e Natureza: contribuições da obra 'O Príncípio Responsabilidade', de Hans Jonas para a Educação Ambiental. In ENCONTRO PESQUISA EM EDUCAÇÃO AMBIENTAL, 9, 2017, Juiz de Fora. Anais... Juiz de Fora: UFJF, 2017. p. 1-12. Disponível em: http://epea.tmp.br/epea2017_anais/pdfs/plenary/0197.pdf. Acesso em: 5 ago. 2018.

TRAWITZKI, H.; RINK, J. A Ecopedagogia na Produção acadêmica Nacional em Educação Ambiental: uma análise de dissertações e teses (1981-2012). . In ENCONTRO PESQUISA EM EDUCAÇÃO AMBIENTAL, 9, 2017, Juiz de Fora. Anais... Juiz de Fora: UFJF, 2017. p. 1-13. Disponível em: http://epea.tmp.br/epea2017_anais/pdfs/plenary/0200.pdf. Acesso em: 5 ago. 2018.

TREIN, E.; CAVALARI, R. M. F. Pesquisa em Educação Ambiental e Questões Epistemológicas: a permanência e a renovação. Pesquisa em Educação Ambiental, Rio Claro, v. 9, n. 1, p.120-132, jan./jun., 2014.

TREIN, E. Pesquisa em Educação Ambiental e Epistemológicas: questões levantadas no GDP. Pesquisa em Educação Ambiental, Rio Claro, v. 7, n.2, p. 79-89, jul./dez. 2012.

UCHÔA, R.; CASTRO, L. de; SÁNCHEZ, C. Análise da Década da Educação para o desenvolvimento Sustentável (DEDS) da Unesco a partir da leitura da Pedagogia da Autonomia de Paulo Freire. In ENCONTRO PESQUISA EM EDUCAÇÃO AMBIENTAL, 9, 2017, Juiz de Fora. Anais... Juiz de Fora: UFJF, 2017. p. 1-13. Disponível em: epea.tmp.br/epea2017_anais/pdfs/plenary/0254.pdf. Acesso em: 5 ago. 2018. 